\title{
Comparative study of labour progress and delivery outcome among induced versus spontaneous labour in nulliparous women using modified WHO partograph
}

\author{
Ernest O. Orii, Taofeek O Olabode
}

Department of Obstetrics Gynaecology and Perinatology, Obafemi Awolowo University, Ile-Ife, Nigeria

\begin{abstract}
Aim: Induced or spontaneous labour has implication on the eventual mode of delivery and neonatal outcome. The objective of this study is to compare the progress and outcome of induced versus spontaneous labour among nulliparous women using the modified WHO partograph.

Methods: Comparative study involving nulliparous women in active phase of labour with the cervix at least $4 \mathrm{~cm}$ dilated. Those whose labours were induced were compared with those on spontaneous labour; both labouring women were monitored using modified WHO partograph. Outcome measures include the mean duration of labour, the eventual mode of delivery and the feto-material outcome. Data were managed using SPSS software. Chi-square t-test and student t-test were used in data analysis. Level of significance was placed at $\mathrm{P}<0.05$.
\end{abstract}

Results: 136 women were compared in each group. There were no difference in mean age group, gestational age at delivery, cervical dilatation on admission, and the level of head of fifth palpable on admission. More women had spontaneous vaginal delivery among those in spontaneous labour $(72.1 \%$ versus $64.7 \%)$ $\mathrm{P}=0.0001$. There were less caesarean section among those in spontaneous labour (20.6\% versus $35.3 \%)$. The mean Apgar scores were significantly better among induced labour babies ( $P=0.0001)$. While most induced labour cases reached or crossed action line compared to spontaneous labour (33.1\% versus $16.9 \%$ $\mathrm{P}=0.002)$, there were more cases in spontaneous labour moving between alert and action line $(27.9 \%$ versus $9.6 \%, \mathrm{P}=0.000$ )

Conclusion: Induced labour monitored with modified WHO partograph is comparative to spontaneous labour with no increased adverse feto maternal outcome.

Key words: Induced versus spontaneous labour; modified WHO partograph, labour outcome.

\section{Introduction}

Induction of labour is the artificial initiation of uterine contractions prior to their spontaneous onset, leading to progressive dilatation and effacement of the cervix and delivery of the baby. ${ }^{1,2}$

The indication of induction of labour must be acceptable as also being sufficient indications for a caesarean section because if the procedure fails, the end result is caesarean section. ${ }^{3,4}$ It has been observed that for all intents and purposes, failed induction is commoner among primigravida and nulliparous women especially those with unfavorable cervix prior to induction. ${ }^{5}$ Due to this, there is often a great aversion for induction of labour among nulliparous women in our environment because if the induction fails, the next option is caesarean section which may adversely affect the mode of delivery in subsequent pregnancies. ${ }^{6,7}$

In an environment such as ours with great aversion for caesarean section ${ }^{6,7}$ most women prefer spontaneous labour due to the presumed belief that it is associated with better fetomaternal outcome. ${ }^{8}$ Furthermore

Correspondence

Dr. E.O. Orji, FMCOG, FWACS

Assoc Prof, Department of Obstetrics and Gynaecology, Oau ile-ife

Email:eoorji11@yahoo.com

Mobile: +2348033567451 
nulliparous women have been described as a group at risk in labour. This is because their capacity for childbearing has never previously been put to test. They cannot be relied upon to run to form. ${ }^{9}$ In developing countries, like Nigeria all nulliparous labour had been regarded as trial of labour because of the high rate of cephalopelvic disproportion. ${ }^{10}$

There is scarcity of literature comparing spontaneous versus induced labour among nulliparous women. It is pertinent to compare the outcome of labour among these groups using World Health Organization (WHO) partograph. ${ }^{11-16}$ Our study hypotheses that if both types of labour are monitored using the modified WHO partograph (see figure 1) in which the labour must have been established, in active phase with cervical dilatation of at least $4 \mathrm{~cm}$ dilated, the outcome of labour may be similar. The findings from the study are likely to alley the anxiety over induction of labour among nulliparous women due to fear of caesarean section arising from failed induction.

\section{Methods}

This prospective comparative study was carried out at the Obstetric Department of Obafemi Awolowo University Teaching Hospital Complex, Wesley Guild Hospital Ilesa, from January 20006 to October 2007. The study included all nulliparous pregnant women at term requiring induction of labour with live singleton fetuses in vertex presentation. The women were eligible to be recruited once the cervix is $4 \mathrm{~cm}$ dilated since the new WHO partograph commenced at $4 \mathrm{~cm}$ dilatation. Those with unfavourable cervix had pre-induction cervical ripening with 25 microgram of misoprostol. Exclusion criteria were contracted pelvis, medical conditions during pregnancy, intrauterine growth restriction, antepartum haemorrhage.

The sample size was calculated using $21.4 \%$ incidence of failed induction in this health facility using the statistical formula.

$$
\mathrm{n}=\frac{1}{(1-\mathrm{F})} \mathrm{X}\left[\mathrm{ZX}\left(\mathrm{Z}_{1}+\mathrm{Z}_{\underline{\mathrm{p}}}\right)^{2} \frac{\mathrm{XPX}(1-\mathrm{P})]}{\mathrm{P}_{0}-\mathrm{P}_{1}}\right.
$$

Where $\mathrm{n}$ represents minimum sample size;

$\mathrm{P}_{0}$ the incidence rate in the pilot study (21.4\%) or (0.214). $\mathrm{P}_{1}$, the proportion of participants in the induction group set relative to $\mathrm{P}_{0}$ assuming that the failure rate of labour induction would be reduced by $25 \%$ by inducing the labour.

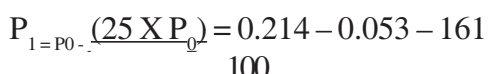

$\mathrm{Z}_{1}$ the level of significance at 0.05 , which was 1.96 $\mathrm{Z}_{\mathrm{p}}$ the power of $90 \%(0.90)$, was $1.28 ; \mathrm{F}$; The proportion lost to follow up was 0 .

Therefore,

$$
\begin{gathered}
\mathrm{N}=1 \times 2 \times(1.96+1.28)^{2} \\
\text { (approximately }
\end{gathered} \frac{0.187 \times 0.813}{60 \text { women })}=60.22
$$

To increase the level of significance a sample size of 136 women were used per group (total of 272). 136 nulliparous women requiring induction of labour who fulfilled the inclusion criteria were serially recruited and compared with 136 consecutive nulliparous women who had spontaneous labour. Data was arranged using statistical package for social sciences (SPSS). Level of significance was placed at $5 \%(\mathrm{P}<0.05)$.

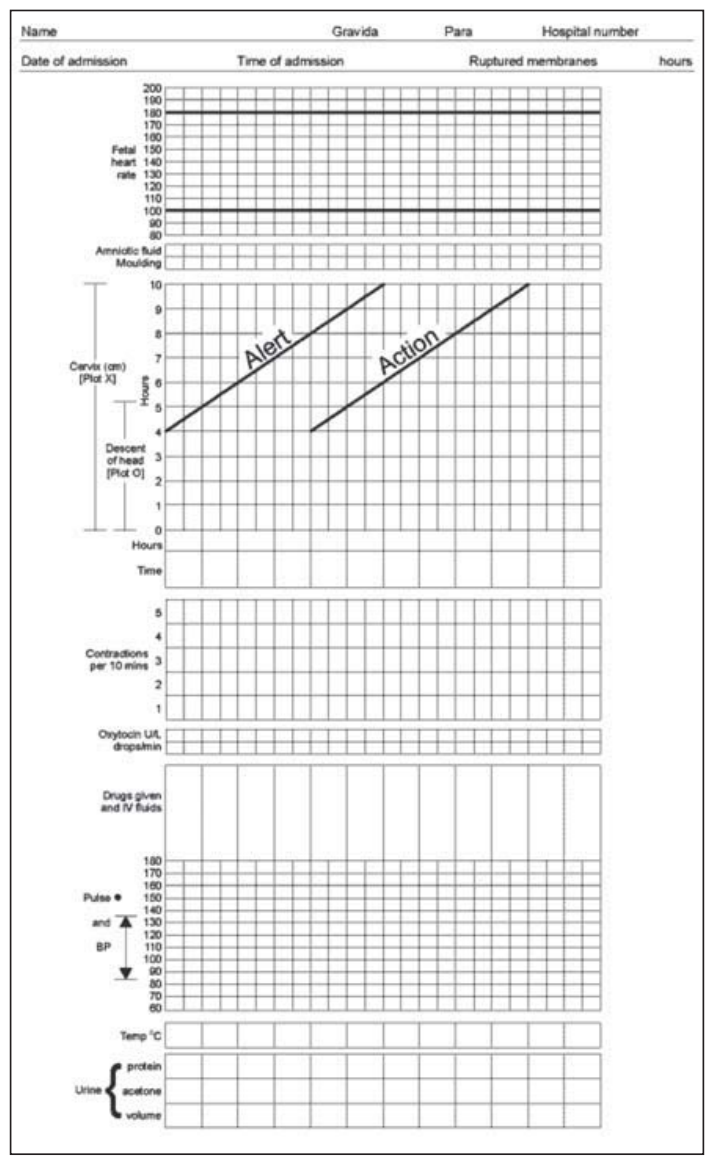

Modfied WHO Partograph

\section{Result}

Table I, shows selected demographic characteristics. There was no significant difference among both groups in the mean age, gestational age, cervical dilatation on admission, and level of head of fifth palpable per admission. Table II shows the labour outcome. There was no significant difference in total duration of labour $(\mathrm{P}=0.131)$. 
Ernest O. Orji, Taofeek O Olabode

Table I. Selected Characteristics of Comparison Group

\begin{tabular}{lccc}
\hline Variable & $\begin{array}{c}\text { Spontaneous labour } \\
(\mathrm{n}=136) \\
\text { Mean } \pm \text { SD }\end{array}$ & $\begin{array}{c}\text { Induced labour } \\
(\mathrm{n}=\text { | 36) } \\
\text { Mean } \pm \text { SD }\end{array}$ & $\begin{array}{c}\text { Statistical } \\
\text { Analysis }\end{array}$ \\
\hline Age (years) & $28.43 \pm 6.45$ & $28.44 \pm 6.43$ & $\mathrm{t}=1.076 \mathrm{p}=2.82$ \\
Gestational age (weeks) & $39.38 \pm 1.186$ & $39.52 \pm 1.785$ & $\mathrm{t}=0.800 \mathrm{p}=0.424$ \\
Cervical dilatation on admission $(\mathrm{cm})$ & $4.68 \pm 1.001$ & $4.55 \pm 0.778$ & $\mathrm{t}=1.217 \mathrm{p}=0.225$ \\
Level of head of fifth palpable & $3.22 \pm 0.875$ & $3.26 \pm 0.981$ & $\mathrm{t}=0.326 \mathrm{p}=0.745$ \\
\hline
\end{tabular}

Table 2. Labour Outcome among Comparison Group

\begin{tabular}{lccc}
\hline \multicolumn{1}{c}{ Labour outcome } & $\begin{array}{c}\text { Spontaneous labour } \\
\text { Mean } \pm \text { SD }\end{array}$ & $\begin{array}{c}\text { Induced labour } \\
\text { Mean } \pm \text { SD }\end{array}$ & $\begin{array}{c}\text { Statistical } \\
\text { Analysis }\end{array}$ \\
\hline Total duration of labour (hours) & $6.080 \pm 2.397$ & $6.507 \pm 2.237$ & $\begin{array}{c}\mathrm{t}=1.314 \\
\mathrm{P}=0.131 \\
\mathrm{X}^{2}=15.801 \\
\mathrm{P}=0.001^{\mathrm{xxx}}\end{array}$ \\
$\begin{array}{l}\text { Mode of delivery Spontaneous } \\
\text { Vaginal Delivery }\end{array}$ & $98(72.1 \%)$ & $88(64.7 \%)$ & \\
Caesarean Section & $28(20.6 \%)$ & $48(35.3 \%)$ & \\
Operative Vaginal Delivery & $10(7.3 \%)$ & $33(24.3 \%)$ & $\mathrm{X}^{2}=14.66$ \\
$\begin{array}{l}\text { Indication for Surgery Cephalopelic } \\
\text { Disproportion }\end{array}$ & $17(12.5 \%)$ & & $\mathrm{P}=0.0001^{\mathrm{xxx}}$ \\
Fetal Distress & $10(7.3 \%)$ & $10(7.3 \%)$ & - \\
Failure to Progress & $9(6.62 \%)$ & & \\
\hline
\end{tabular}

$x x x$ very Significant at $P<0.05$

Table 3. Neonatal Outcome among Comparison Group

\begin{tabular}{lccc}
\hline Neonatal Outcome & $\begin{array}{c}\text { Spontaneous labour } \\
\text { Mean } \pm \text { SD }\end{array}$ & $\begin{array}{c}\text { Induced labour } \\
\text { Mean } \pm \text { SD }\end{array}$ & $\begin{array}{c}\text { Statistical } \\
\text { Analysis }\end{array}$ \\
\hline Apgar Scores at 1 minute & $7.68 \pm 2.50$ & $8.72 \pm 1.05$ & $\begin{array}{c}\mathrm{t}=4.454 \\
\mathrm{p}=0.001^{\mathrm{xxx}}\end{array}$ \\
$\begin{array}{l}\mathrm{t}=2.891 \\
\mathrm{p}=0.008^{\mathrm{xxx}}\end{array}$ & $9.45 \pm 1.10$ & \\
$\begin{array}{l}\text { Apgar Scores at } \mathbf{5} \text { minute } \\
\text { Alive }\end{array}$ & $8.93 \pm 1.87$ & $136(100 \%)$ & $\begin{array}{c}\mathrm{X}^{2}=31.213 \\
\mathrm{p}=0.0001^{\mathrm{xxx}}\end{array}$ \\
\hline
\end{tabular}

xxx very significant at $P<0.05$

Table 4. Evaluation of Progress in Labour using Modified WHO Partograph

\begin{tabular}{lccc}
\hline Neonatal Outcome & $\begin{array}{c}\text { Spontaneous labour } \\
(\mathrm{n}=136)\end{array}$ & $\begin{array}{c}\text { Induced labour } \\
(\mathrm{n}=136)\end{array}$ & $\begin{array}{c}\text { Statistical } \\
\text { Analysis }\end{array}$ \\
\hline Normal Active Phase & $75(55.1 \%)$ & $78(57.4 \% 0$ & $\begin{array}{c}\mathrm{X}^{2}=0.134 \\
\mathrm{p}=0.714\end{array}$ \\
Moved between Alert and Action line & $38(27.9 \%)$ & $13(9.6 \% 0$ & $\begin{array}{c}\mathrm{X}^{2}=15.083 \\
\mathrm{p}=0.000^{\mathrm{xxx}}\end{array}$ \\
Reached or Crossed Action Line & $23(16.9 \%)$ & $45(33.1 \%)$ & $\begin{array}{c}\mathrm{X}^{2}=9.490 \\
\mathrm{p}=0.002^{\mathrm{xxx}}\end{array}$ \\
\hline
\end{tabular}

NB: $\mathrm{xxx}$ very significant at $\mathrm{P}<0.05$ 
Greater percentage of those with spontaneous labour had spontaneous vaginal delivery $(72.1 \%$ versus $64.7 \%)$. In contrast more of those with induced labour had caesarean section (35.3\% versus $20.6 \%)(\mathrm{P}=0.001)$. Table III shows the neonatal outcome Apgar scores at 1 and 5 minutes were significantly better among those with induced labour compared at those in spontaneous labour. Table IV shows the progress of labour. There was no difference between both groups in the progress in normal active phase of labour. More women in spontaneous labour had their cervical dilation moving between alert and action line $(27.9 \%$ versus $9.6 \%) \mathrm{P}=$ 0.000 .

In contrasts more of those with induced labour had their labour reached or crossed action line $(33.1 \%$ versus $16.9 \%) \mathrm{P}=0.002$.

\section{Discussion}

This study revealed pertinent findings which is very useful in labour management among nulliparous women. There were no significant difference in the mean age, gestational age (in weeks), cervical dilation on admission and the level of head of fifth palpable at admission among comparison group. This signifies that the finding from the study could be relied on to be true reflection of labour outcome among comparison group. The mean total duration of labour among comparison group was similar (6.080 versus 6.507 hours). This is less that the mean duration of 8.83 hours reported among primigravidae in spontaneous labour in uncomplicated pregnancies in the same study centre five year previously. ${ }^{8}$

This may be due to the fact that while our study utilized the modified WHO partograph (see figure 1) in which plotting is commenced at cervical dilatation of at least $4 \mathrm{~cm}$, the previous study utilized the old partograph which have both latent and active phase of labour.

However the fact that the mean total duration of labour is similar among induced versus spontaneous labour is an assonance that induced labour is not necessarily associated with prolonged labour.

This may also be due to the use of partograph which ensures that all parturient are actively managed ${ }^{11-14}$ and easily detection of slow progress of labour can alert a warning for intervention to prevent obstructed labour. ${ }^{11,14}$

This is vividly shown in the table IV in which the progress of labour was evaluated. It could be seen in that table that there were similar normal active phase in comparison group $(55.1 \%$ versus $57.4 \% \mathrm{P}=0.714)$.
However, more women in spontaneous labour moved between alert and action lines $(27.9 \%$ versus $9.6 \%$ among induced group). This is statistically significant at $\mathrm{P}=0.000$.

This led to earlier intervention among spontaneous labour group leading to less proportion of them reaching or crossing action line $(16.9 \%$ compared to $33.1 \%$ among induced group). This showed statistically significant at $\mathrm{P}=0.002$.

Larger proportion of women in spontaneous labour group achieved spontaneous vaginal delivery compared to induced labour group $(72.1 \%$ versus $64.7 \%$ ). There were also lesser proportion of caesarean section among spontaneous labour group compared to induced labour group ( $20.6 \%$ versus $35.3 \%$ ). This is in keeping with observations in the literature ${ }^{11-16}$. However despite these apparent advantages, the neonatal Apgar Scores at 1 and 5 minutes were better among babies delivered by induced labour compared to those in spontaneous labour. This shows statistical significant difference. The eventual neonatal outcome showed that there were two fresh still births among spontaneous labour group compared to none among those of induced labour. The cause of these fresh still births were cord tightly round the neck of the fetus, which was not suspected while labour were being augmented for slow progress among these women in spontaneous labour.

\section{Conclusion}

We can draw from this study that while induced labour may increase the chances of caesarean section, it does not adversely affect the neonatal outcome. We therefore advise that induced labour can be a safe procedure among nulliparous women if labour is partographically monitored. We further advise that when labour progress becomes slow in spontaneous labour, a high index of suspicious for cord accident should be borne in mind after excluding cephalopelvic disproportion.

\section{References}

1. Brennand J, Greer I. Induction of labour: New Horizons. Hospital Medicine 1998; 59: 856-860.

2. Royal College of Obstetricians and Gynaecologists. Induction of labour. London RCOG Press 1998, Guidance No 16.

3. Orhue AAE. Induction of labour. Trop J Obst Gynecol 1997; 14 (1): 1-4. 
4. Durodola A, Kuti O, Orji EO, Ogunniyi SO. Rate of increase in oxytocin dose on the outcome of labour induction. Int J Obstet Gynaecol 2005, 10: 107-111.

5. Lewis TLT, Chamberlain GVP(eds): Induction of labour: In Obstetrics by Ten Teachers 15th edition Edward Arnold Publishers, London 1990: pages 275-277.

6. Orji EO, Ogunniyi SO, Onwudiegwu U. Belief and Perception of Pregnant Women at Ilesa about Caesarean Section - Trop J. Obstet Gynaecol 2003; 20(1): $28-31$.

7. Fasubaa OB, Ogunniyi SO, Dare FO, Isawunmi AI, Ezechi OC, Orji EO. Uncomplicated Caesarean Section: Is prolonged Hospital Stay necessary. EAMJ 2000; 77(8): 36-39.

8. Kuti O, Orji EO, Owolabi AT. Outcome of Spontaneous labour in uncomplicated pregnancies in Nigerian Population. Trop J Obstet Gynaecol 2006; 23(2): 137 - 140.

9. Beazley JM. Special Circumstances Affecting Labour. In Dewhurst's Textbook of Obstetric and Gynaecology for Postgraduate (edited by CR Whitfield); 5th edition. Blackwell Science. Oxford 1995; pages $312-330$.
10. Ekwempu CC. Problems in labour. In textbook of Obstetric and Gynaecology for Medical Students Vol. II. Edited by A Agbooola. USEP Lagos, Nigeria: 1988: 181-200.

11. Orji EO, Fatusi AA, Makinde NO, Adeyemi BA, Onwudiegwu U. Impact of Training on the use of Partograph on maternal and perinatol outcome in peripheral Health Centers. J. Turkish - German Gynaecol Assoc 2007: 8(2): 148 - 152.

12. WHO. Preventing Prolonged Labour. A Practical Guide: The Partograph Part I, Principles and Strategy WHO/FHE/MSM/93.8.

13. WHO. Preventing Prolonged Labour. A practical Guide: The Partograph Part II. Users Manual WHO/FHE/MSM/93.9.

14. WHO. Partograph cuts Complications of Labour and Childbirth, Safe Motherhood 1994: July-Oct. 32:107-10.

15. Gupta S. Active Management of labour with Minor degree of cephalopelvic disproportion. A partogramic study. J Obstet and Gynaecol India: 1987; 37(5): 639-41.

16. WHO. World Health Organization Partograph in Management of Labour. Lancet 1994: 343: 13991404. 